\title{
Distribution of Axial Length, Anterior Chamber Depth and Lens Thickness of Pre-Operative Cataract Patients in Indonesian Population
}

\author{
Titiek Ernawati1,2, Maharani Kartika Anggraeni'2, Kevin Anggakusuma Hendrawan', \\ Rianti Wulandari Pratiwi ${ }^{3}$ \\ ${ }^{1}$ Ophthalmology Department, Faculty of Medicine, Widya Mandala Catholic University Surabaya, Surabaya, Indonesia \\ ${ }^{2}$ Ophthalmology Department, Primasatya Husada Citra Hospital, Surabaya, Indonesia \\ ${ }^{3}$ Faculty of Medicine, Airlangga University, Surabaya, Indonesia \\ Email: titiek_ernawati@yahoo.com
}

How to cite this paper: Ernawati, T., Anggraeni, M.K., Hendrawan, K.A. and Pratiwi, R.W. (2020) Distribution of Axial Length, Anterior Chamber Depth and Lens Thickness of Pre-Operative Cataract Patients in Indonesian Population. Open Journal of Ophthalmology, 10, 288-296.

https://doi.org/10.4236/ojoph.2020.104032

Received: September 2, 2020

Accepted: November 7, 2020

Published: November 10, 2020

Copyright $\odot 2020$ by author(s) and Scientific Research Publishing Inc. This work is licensed under the Creative Commons Attribution International License (CC BY 4.0).

http://creativecommons.org/licenses/by/4.0/

(c) (i) Open Access

\begin{abstract}
Purpose: Biometry measurement of pre-operative cataract patients plays a major role in calculating intraocular lens power. This study aimed to review and determine the distribution of biometry components, such as axial length (AL), anterior chamber depth (ACD), and lens thickness (LT) of pre-operative cataract patient in Indonesian population. Methods: A cross-sectional study data were obtained from 2015-2018 cataract surgery at Prima Husada Citra Hospital, Surabaya, East Java, Indonesia. A total of 1295 eyes with cataract was included in the study based on their medical record. We analyzed the data using descriptive analysis and correlated each variable using the Spearman's Rho analysis. Results: Mean AL, LT and ACD was $23.81 \pm 1.46 \mathrm{~mm}$, $4.49 \pm 0.55 \mathrm{~mm}, 3.25 \pm 0.70 \mathrm{~mm}$ respectively. Male has longer AL and deeper ACD with $(p<0.001)$, while LT was found thicker in female $(p=0.005)$. The increase of AL was accompanied by ACD $(r=0.457 ; p<0.001)$ and a thinner LT $(r=-0.101 ; p<0.001)$. Conclusions: LT is increased with age while AL and ACD are shortened with age. There was a positive correlation between $\mathrm{AL}$ and $\mathrm{ACD}$, but an inverse correlation between AL and LT.
\end{abstract}

\section{Keywords}

Anterior Chamber Depth, Axial Length, Cataract, Lens Thickness

\section{Introduction}

One of the most common surgical procedures in developing countries is cataract surgery. The accuracy of biometry measurement, especially the AL, plays a ma- 
jor role in calculating the intraocular lens power, which is an important factor for the surgery [1] [2] [3]. A previous observational study stated that postoperative ACD depends only on the AL, however, another study showed that postoperative $\mathrm{ACD}$ is related to preoperative biometry components such as $\mathrm{AL}$, ACD, LT, cornea curvature and refraction [4]. This study aimed to review and determine the distribution of biometry components, such as $\mathrm{AL}, \mathrm{ACD}$, and LT of pre-operative cataract patients in Indonesian population. Our study worked with a large sample trying to give a better representation of biometry characteristic in Indonesian population.

\section{Material and Methods}

This cross-sectional study data were obtained from 2015-2018 cataract surgery at Primasatya Husada Citra (PHC) Hospital, Surabaya, East Java, Indonesia. A total of 1295 pre-operative cataract eyes medical records were examined. The inclusion criteria for this study are patients who underwent cataract surgery in the period of year 2015-2018 in PHC Hospital Surabaya with complete medical record data. The exclusion criteria were any co-morbidities in ophthalmology including glaucoma, retinal detachment, traumatic cataract, and any other ophthalmology condition except cataract. Medical records with missing data were excluded from the study. The data of age, sex, AL, ACD and LT were collected based on the medical records.

\section{Results}

In this study, there were 1295 eyes of preoperative cataract patients met the inclusion criteria. The mean age of the patients was $63.57 \pm 9.52$. The mean age of male was $63.49 \pm 10.15$ and the mean age of the female was $63.63 \pm 8.95$. Table 1 shows the demographic characteristic of the patients. The mean of biometry parameters are shown in Table 2.

Independent t-test showed a significant difference between AL, LT and ACD between group of sex. Both AL and ACD were longer and deeper in male while LT mean was found thicker in female as shown in Table 3.

Table 1. Summary of demographic profile of Cataract patient.

\begin{tabular}{|c|c|}
\hline Baseline Characteristic & Value \\
\hline \multicolumn{2}{|l|}{ Sex } \\
\hline Male N (\%) & $598(46.2 \%)$ \\
\hline Female N (\%) & $697(53.8 \%)$ \\
\hline Age Mean \pm SD & $63.57 \pm 9.52$ \\
\hline \multicolumn{2}{|l|}{ Laterality } \\
\hline Right Eye & $665(51.4 \%)$ \\
\hline Left Eye & $630(48.6 \%)$ \\
\hline
\end{tabular}


As shown in Table 4 and Figure 1, most of the patients were aged $56-65$ and patients aged 66 - 75 were ranked second. Figure 2 and Figure 3 further explain the distribution of AL, LT, and ACD by the group of age. As shown in Figure 2, in our study the axial length decreases by age. Figure 3 shows how LT increases with age whereas ACD decreases with the increment of the LT and Age. This correlation between age, ACD, and LT is further discussed in Table 5 .

Figure 4 showed the distribution of axial length was skewed toward myopic side but increased in the last category $(>27.00 \mathrm{~mm})$. The shortest axial length in the first category was $13.30 \mathrm{~mm}$, while the longest axial length was $37.63 \mathrm{~mm}$. About 548 of 1295 (42.3\%) eyes were categorized in 23.00 - 23.99 group of AL. Mean AL was $23.81 \pm 1.46 \mathrm{~mm}$. The distribution of lens thickness ranges between the thinnest lens $(1.36 \mathrm{~mm})$ and the thickest lens $(8.73 \mathrm{~mm})$. The majority of eyes (457 of 1295) were having thickness between $4.50-4.99 \mathrm{~mm}$.

Table 2. Patient's baseline characteristic.

\begin{tabular}{cc}
\hline Baseline Characteristic & Value \\
Axial Length Mean \pm SD $(\mathrm{mm})$ & $23.81 \pm 1.46$ \\
Lens thickness Mean \pm SD $(\mathrm{mm})$ & $4.49 \pm 0.55$ \\
Anterior Chamber Depth Mean \pm SD $(\mathrm{mm})$ & $3.25 \pm 0.70$ \\
\hline
\end{tabular}

Table 3. Mean distribution by sex.

\begin{tabular}{cccc}
\hline & Male & Female & p-value \\
\hline $\mathrm{AL}$ & $24.01 \pm 1.34 \mathrm{~mm}$ & $23.63 \pm 1.53 \mathrm{~mm}$ & $<0.001$ \\
$\mathrm{LT}$ & $4.44 \pm 0.54 \mathrm{~mm}$ & $4.53 \pm 0.55 \mathrm{~mm}$ & 0.005 \\
$\mathrm{ACD}$ & $3.38 \pm 0.90 \mathrm{~mm}$ & $3.14 \pm 0.42 \mathrm{~mm}$ & $<0.001$ \\
\hline
\end{tabular}

Table 4. Distribution of AL, LT, and ACD as mean by sex and age.

\begin{tabular}{|c|c|c|c|c|}
\hline & n (\%) & $\begin{array}{c}\mathrm{AL}(\mathrm{mm}) \\
\text { Mean } \pm \mathrm{SD}\end{array}$ & $\begin{array}{c}\mathrm{LT}(\mathrm{mm}) \\
\text { Mean } \pm \mathrm{SD}\end{array}$ & $\begin{array}{l}\mathrm{ACD}(\mathrm{mm}) \\
\text { Mean } \pm \mathrm{SD}\end{array}$ \\
\hline \multicolumn{5}{|l|}{ Sex } \\
\hline Male & $598(46.2 \%)$ & $24.01 \pm 1.34$ & $4.44 \pm 0.54$ & $3.38 \pm 0.90$ \\
\hline Female & 697 (53.8\%) & $23.63 \pm 1.53$ & $4.53 \pm 0.55$ & $3.14 \pm 0.42$ \\
\hline \multicolumn{5}{|l|}{ Age } \\
\hline$<46$ & $48(3.7 \%)$ & $24.01 \pm 1.93$ & $4.45 \pm 0.90$ & $3.27 \pm 0.47$ \\
\hline $46-55$ & $179(13.8 \%)$ & $24.29 \pm 1.93$ & $4.30 \pm 0.48$ & $3.41 \pm 0.43$ \\
\hline $56-65$ & $517(39.9 \%)$ & $23.80 \pm 1.41$ & $4.46 \pm 0.52$ & $3.29 \pm 0.97$ \\
\hline $66-75$ & $434(33.5 \%)$ & $23.71 \pm 1.21$ & $4.58 \pm 0.53$ & $3.16 \pm 0.39$ \\
\hline$>75$ & $117(9.0 \%)$ & $23.38 \pm 1.27$ & $4.56 \pm 0.55$ & $3.14 \pm 0.42$ \\
\hline
\end{tabular}


Table 5. Spearman's correlation age.

\begin{tabular}{cccc}
\hline & AL & LT & ACD \\
\hline Age & $\mathrm{r}=-0.115$ & $\mathrm{r}=0.173$ & $\mathrm{r}=-0.184$ \\
& $p<0.001$ & $p<0.001$ & $p<0.001$ \\
$\mathrm{AL}$ & - & - & $\mathrm{r}=0.457$ \\
& & & $p<0.001$ \\
$\mathrm{LT}$ & - & - & $\mathrm{r}=-0.101$ \\
& & & $p<0.001$ \\
\hline
\end{tabular}

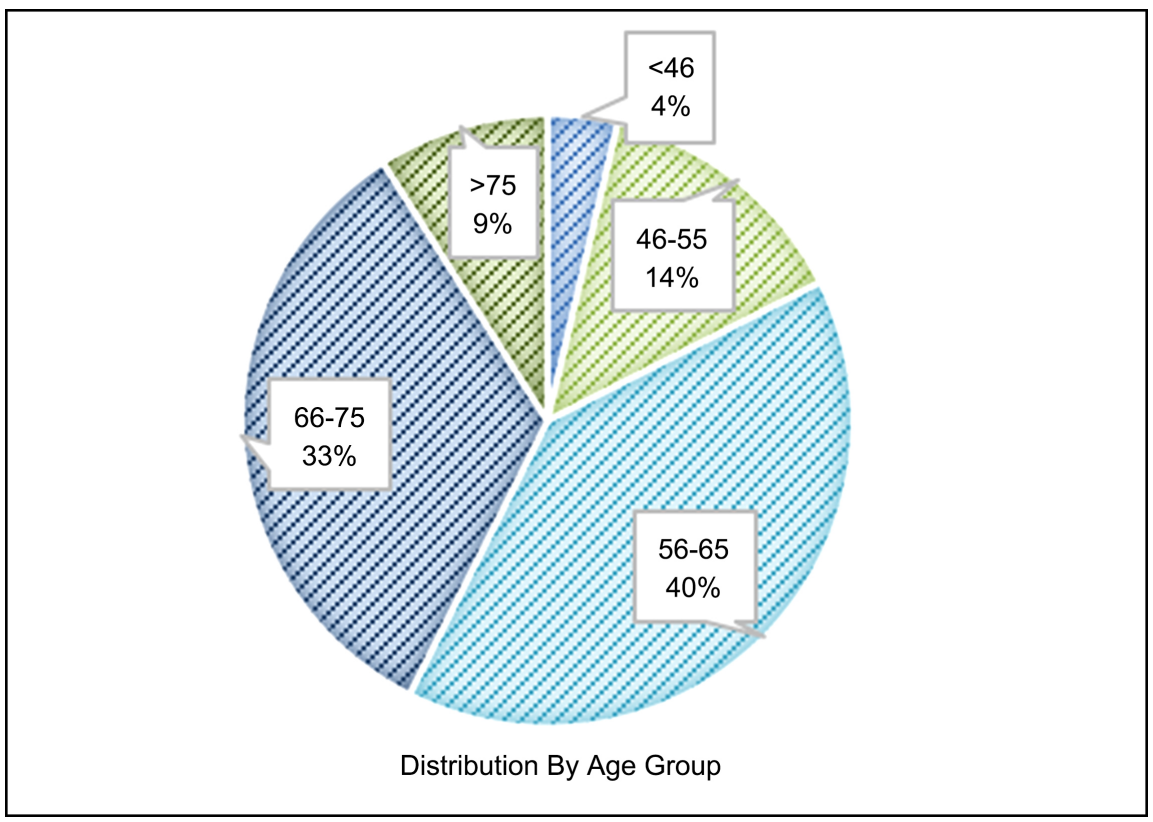

Figure 1. Distribution by age group.

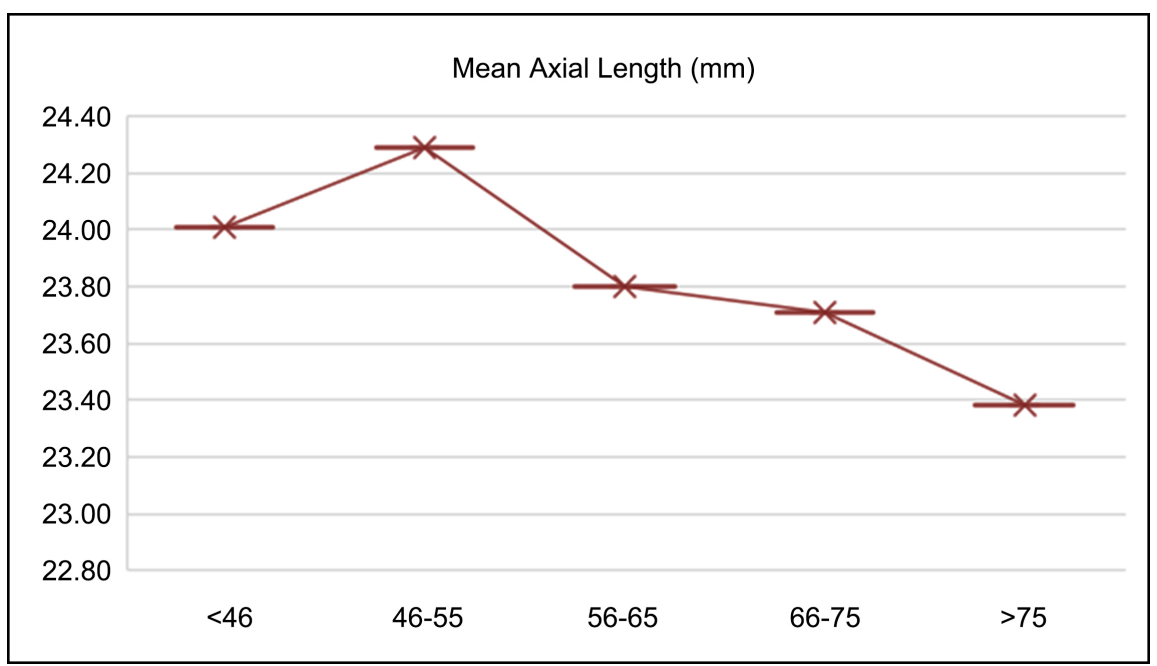

Figure 2. Distribution of axial length mean by age group. 


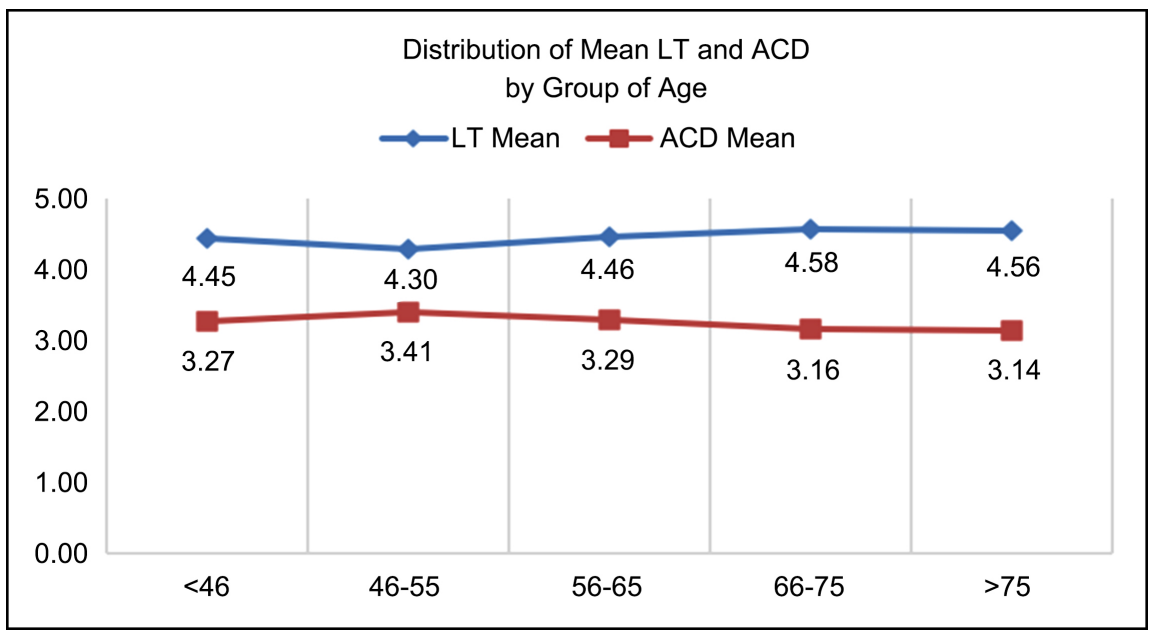

Figure 3. Distribution of lens thickness and anterior chamber depth mean by age group.

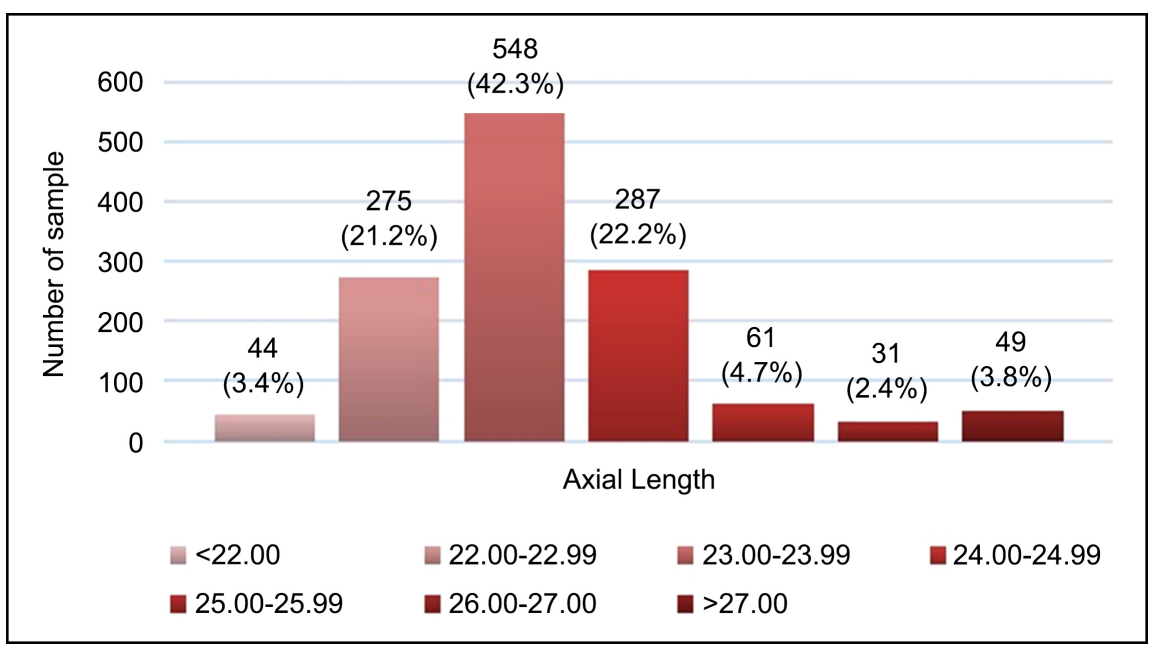

Figure 4. Distribution of axial length characteristic.

Table 5 comprises the correlation between age, AL, and LT. A positive correlation between age and LT was found in this study, however, age, AL and ACD were an inverse correlation. Older patients tend to have thicker lens $(r=0.173 ; p$ $<0.001)$. The increase of age is followed by shorter AL $(r=-0.115 ; p<0.001)$ and shallower ACD $(r=-0.184 ; p<0.001)$. Table 5 shows the correlation of $\mathrm{ACD}$ and LT to the AL. The increase of AL was followed by a profound ACD $(r$ $=0.457 ; p<0.001)$ and a thinner LT $(r=-0.101 ; p<0.001)$.

\section{Discussion}

The goal of cataract surgery is to give the best accuracy of refractive errors. The refractive errors after surgery are resulting from the intraocular lens (IOL) and corneal cylinder in patients with normal retinal and optic nerve function. IOL power calculation is influenced by ocular biometry such as AL, ACD, LT and K. Besides the ocular biometry, the other important factor is the position and stability of IOL which can be measure by the ACD which represent the effective 
lens position (ELP) [5].

In this study, the mean ACD was $3.25 \pm 0.70 \mathrm{~mm}$. Another study in Iran showed the mean ACD was $2.62 \mathrm{~mm}$ which is lower than our study [6]. The mean ACD was comparable with a study in South China (3.13 mm), Myanmar $(2.81 \mathrm{~mm})$ and USA $(2.86 \pm 0.45 \mathrm{~mm})$ [7] [8] [9]. Our study showed that the mean ACD is greater in male with $3.38 \pm 0.90 \mathrm{~mm}$ than female $3.14 \pm 0.42 \mathrm{~mm}$. Similar gender difference also showed in Reykjavik Eye Study with mean ACD in male $3.20 \mathrm{~mm}$ and female $3.08 \mathrm{~mm}$ [10]. In Mongolian population, a report also stated that ACD in male is greater than female, with $2.87 \mathrm{~mm}$ and $2.77 \mathrm{~mm}$ [11]. Meanwhile, a study in BMES showed that the ACD is greater in female than male with $3.06 \mathrm{~mm}$ and $3.04 \mathrm{~mm}$ [3].

As shown in Table 6, we compare our mean AL which is slightly higher than study in the USA, South China, Iran and Myanmar where the mean AL was $23.46 \pm 1.03 \mathrm{~mm}, 23.48 \mathrm{~mm}$ (23.40 - 23.55), $23.14 \mathrm{~mm}$ and $22.76 \mathrm{~mm}$ consecutively [6] [7] [8] [9]. We found that mean AL is slightly higher in male (24.01 \pm $1.34 \mathrm{~mm})$ than female $(23.63 \pm 1.53 \mathrm{~mm})$. This study also consistent with several studies that also showed that male has higher axial length than female. In Iranian population study showed axial length in male 23.41 (23.37 - 23.46) is longer than in female 22.95 (22.91 - 22.98) [6]. A study in Blue Mountain Eye Study within 10 years showed the mean AL is greater in male $23.76 \mathrm{~mm}$ than in female 23.19 $\mathrm{mm}$ [3] [12]. In an age population in South China male AL (23.68 mm) was significantly longer than female AL (23.23 mm) [8].

Our study showed that mean LT is $4.49 \pm 0.55 \mathrm{~mm}$. This is thicker than the study in Iran where the mean was $4.28 \mathrm{~mm}(4.27$ - 4.29) [6], but thinner compare with the study in the USA where the mean LT was $4.93 \pm 0.56 \mathrm{~mm}(3.03$ $6.41 \mathrm{~mm}$ ) [9]. Our study found the mean of LT were thicker in female $(4.53 \pm$ $0.55 \mathrm{~mm}$ ) than male $(4.44 \pm 0.54 \mathrm{~mm})$. This result was different compared to a study in Iranian population where male has shorter LT $(3.68-4.85 \mathrm{~mm})$ than female (3.71 - $4.90 \mathrm{~mm})$ [6].

Our study found a correlation between age with AL, ACD and LT. AL was shortened with the increase of age and ACD were shallowed whole LT increasing with age. Similar with our study, an Iranian study found that AL and ACD were shortened with age and LT increased [6].

Table 6. Comparison of AL and ACD current and previous.

\begin{tabular}{ccc}
\hline Study & Axial Length $(\mathrm{AL})$ & Anterior Chamber Depth (ACD) \\
\hline Iran & $23.14 \mathrm{~mm}$ & $2.62 \mathrm{~mm}$ \\
South China & $23.48 \mathrm{~mm}$ & $3.13 \mathrm{~mm}$ \\
Myanmar & $22.76 \mathrm{~mm}$ & $2.81 \mathrm{~mm}$ \\
USA & $23.46 \pm 1.03 \mathrm{~mm}$ & $2.86 \pm 0.45 \mathrm{~mm}$ \\
Indonesia & $23.81 \pm 1.46 \mathrm{~mm}$ & $3.25 \pm 0.70 \mathrm{~mm}$ \\
\hline
\end{tabular}


A study in Los Angeles Latino Eye Study Group also showed that older individuals had shallower ACDs $(P<0.001)$ [13]. Another study in an older Caucasian population found that from age 59 years or older, there is a mean reduction for $0.12 \mathrm{~mm}$ per decade in women and $0.02 \mathrm{~mm}$ in men [14]. Jivrajka et al., showed that AL was found to be longer $(\mathrm{r}=-0.127 ; P<0.001)$ and ACD was found deeper $(\mathrm{r}=-0.250 ; P<0.001)$ in younger individuals, while LT tended to be thicker $(\mathrm{r}=0.385 ; P<0.001)$ in older individuals [9]. The trend for an axial length decrease that is in parallel to aging was also found in researches done in the US, China, India, and Mexico [3] [15] [16].

Also linear with our study, a study in Nigeria showed a positive correlation between $\mathrm{AL}$ and ACD. This study stated that a $1 \mathrm{~mm}$ increment of AL is associated with $0.07 \mathrm{~mm}$ increment of ACD [17]. Results in our study was also similar with a study conducted in South Africa which found a positive correlation between AL and ACD $(\mathrm{r}=0.66 ; p<0.001)$ and negative correlation between LT and $\mathrm{ACD}(\mathrm{r}=-0.68 ; p<0.001)[18]$.

The increasing of AL was followed by a deeper $\mathrm{ACD}(r=0.423 ; p=001)$ and a thinner LT ( $r=0.179, p=001)$ [9]. There was positive correlation between AL and ACD [3]. Jivrajka et al., shows the increase in AL was followed by the deeper $\operatorname{ACD}(r=0.423 ; p=001)$ and thinner AL $(r=0.179, p=001)$ [9]. Similar with the previous study, Fotedar et al. also reported a positive correlation between $\mathrm{AL}$ and ACD [3].

The increasing of AL was followed by a deeper ACD $(r=0.423 ; p=001)$ and a thinner LT ( $r=0.179, p=001)$ [9]. There was positive correlation between AL and ACD [3]. Jivrajka et al., shows the increase in AL was followed by the deeper $\operatorname{ACD}(r=0.423 ; p=001)$ and thinner AL $(r=0.179, p=001)$ [9]. Similar with the previous study, Fotedar et al. also reported a positive correlation between $\mathrm{AL}$ and ACD [3].

\section{Conclussion}

LT is increased with age while AL and ACD are shortened with age. There was a positive correlation between $\mathrm{AL}$ and $\mathrm{ACD}$, but an inverse correlation between $\mathrm{AL}$ and $\mathrm{LT}$.

\section{Conflict of Interest}

The authors declare no conflicts of interest regarding the publication of this paper.

\section{References}

[1] Nizamani, N.B., Surhio, S.A., Memon, S. and Talpur, K.I. (2014) Axial Length Variability in Cataract Surgery. Journal of College of Physicians and Surgeons Pakis$\tan , 24,918-921$.

[2] Bhardwaj, V. and Rajeshbhai, G.P. (2013) Axial Length, Anterior Chamber Depth-A Study in Different Age Groups and Refractive Errors. Journal of Clinical and Diagnostic Research, 7, 2211-2212. 
https://doi.org/10.7860/JCDR/2013/7015.3473

[3] Fotedar, R., Wang, J.J., Burlutsky, G., Morgan, I.G., Rose, K., Wong, T.Y., et al. (2010) Distribution of Axial Length and Ocular Biometry Measured Using Partial Coherence Laser Interferometry (IOL Master) in an Older White Population. Ophthalmology, 117, 417-423. https://doi.org/10.1016/j.ophtha.2009.07.028

[4] Olsen, T. (2006) Prediction of the Effective Postoperative (Intraocular Lens) Anterior Chamber Depth. Journal of Cataract \& Refractive Surgery, 32, 419-424. https://doi.org/10.1016/j.jcrs.2005.12.139

[5] Ning, X., Yang, Y., Yan, H. and Zhang, J. (2019) Anterior Chamber Depth-A Predictor of Refractive Outcomes after Age-Related Cataract Surgery. BMC Ophthalmology, 19, Article No. 134. https://doi.org/10.1186/s12886-019-1144-8

[6] Hashemi, H., Khabazkhoob, M., Miraftab, M. and Emamian, M.H. (2012) The Distribution of Axial Length, Anterior Chamber Depth, Lens Thickness, and Vitreous Chamber Depth in an Adult Population of Shahroud, Iran. BMC Ophthalmology, 12, Article No. 50. https://doi.org/10.1186/1471-2415-12-50

[7] Warrier, S., Wu, H.M., Newland, H.S., Muecke, J., Selva, D., Aung, T., et al. (2008) Ocular Biometry and Determinants of Refractive Error in Rural Myanmar: The Meiktila Eye Study. British Journal of Ophthalmology, 92, 1591-1594. https://doi.org/10.1136/bjo.2008.144477

[8] Chen, H., Lin, H., Lin, Z., Chen, J. and Chen, W. (2016) Distribution of Axial Length, Anterior Chamber Depth, and Corneal Curvature in an Aged Population in South China. BMC Ophthalmology, 16, Article No. 47. https://doi.org/10.1186/s12886-016-0221-5

[9] Jivrajka, R., Shammas, M.C., Boenzi, T., Swearingen, M. and Shammas, H.J. (2008) Variability of Axial Length, Anterior Chamber Depth, and Lens Thickness in the Cataractous Eye. Journal of Cataract and Refractive Surgery, 34, 289-294. https://doi.org/10.1016/j.jcrs.2007.10.015

[10] Eysteinsson, T., Jonasson, F., Arnarsson, A., Sasaki, H. and Sasaki, K. (2005) Relationships between Ocular Dimensions and Adult Stature among Participants in the Reykjavik Eye Study. Acta Ophthalmologica Scandinavica, 83, 734-738.

[11] Wickremasinghe, S., Foster, P.J., Uranchimeg, D., Lee, P.S., Devereux, J.G., Alsbirk, P.H., et al. (2004) Ocular Biometry and Refraction in Mongolian Adults. Clinical and Epidemiologic Research, 45, 776-783. https://doi.org/10.1167/iovs.03-0456

[12] Nangia, V., Jonas, J.B., Sinha, A., Matin, A., Kulkarni, M. and Panda-Jonas, S. (2010) Ocular Axial Length and Its Associations in an Adult Population of Central rural India: The Central India Eye and Medical Study. Ophthalmology, 117, 1360-1366. https://doi.org/10.1016/j.ophtha.2009.11.040

[13] Shufelt, C., Fraser-bell, S., Mei, Y.L., Torres, M. and Varma, R. (2005) Opalescence in an Adult Population: The Los Angeles Latino Eye Study. Clinical and Epidemiologic Research, 46, 4450-4560. https://doi.org/10.1167/iovs.05-0435

[14] Fotedar, R., Wang, J.J., Burlutsky, G. and Morgan, I.G. (2009) Distribution of Axial Length and Ocular Biometry Measured Using Partial Coherence Laser Interferometry (IOL Master) in an Older White Population. Ophthalmology, 117, 417-423. https://doi.org/10.1016/j.ophtha.2009.07.028

[15] Wani, J.S., Parray, S.I., Keng, M.Q., Majid, O. and Maqbool, A. (2017) Profile of Axial Length in Kashmiri Population with Cataract. International Journal of Medicine and Public Health, 3, 1120-1122.

[16] He, M., Huang, W., Li, Y., Zheng, Y., Yin, Q. and Foster, P.J. (2009) Refractive Er- 
ror and Biometry in Older Chinese Adults: The Liwan Eye Study. National Institutes of Health, 50, 5130-5136.

[17] Aprioku, I. and Ejimadu, C. (2019) Analysis of Ocular Axial Length and Anterior Chamber Depth in Port Harcourt, Nigeria. World Journal of Ophthalmology \& Vision Research, 2, 1-7. https://doi.org/10.33552/WJOVR.2019.02.000535

[18] Mashige, K.P. and Oduntan, O.A. (2017) Axial Length, Anterior Chamber Depth and Lens Thickness: Their Intercorrelations in Black South Africans. African Vision and Eye Health, 76, a362. https://doi.org/10.4102/aveh.v76i1.362 